\title{
Processo Internacional pelos danos socioambientais causados a Equador pelo uso do Glifosato no combate de cultivos ilícitos na Amazônia Colombiana
}

\begin{abstract}
Mónica Montana M. ${ }^{1}$
Resumo

A produção de cultivos ilícitos e o tráfico de drogas no âmbito amazônico tem se convertido numa dinâmica local e regional preocupante, por afetar não apenas as relações societais, mas também por estimular impactos hidroambientais negativos na população e na ambiência. As aspersões aéreas realizadas pelo Estado colombiano na área de fronteira com Equador, para combater o narcotráfico e os plantios ilícitos, resultou num processo jurídico inédito na América do Sul. O Estado equatoriano instaurou demanda na Corte de Haia contra Colômbia, em 2008, devido ao uso de herbicidas tóxicos, entre eles o glifosato. Esse processo trouxe à tona a importância do tema ambiental e colocou em relevo a necessária participação das organizações não governamentais na luta pelos direitos das populações amazônicas na área do conflito. Este artigo sintetiza as circunstâncias em que a demanda se produziu e os argumentos apresentados pelos dois países andino-amazônicos.
\end{abstract}

Palavras Chaves: Impactos Hidroambientais, Glifosato, Narcoguerrilha, Plano Colômbia

\section{INTRODUÇÃO}

Muito embora a coca seja um cultivo ancestral que se desenvolve, sobretudo, nas regiões de altitude e nevoeiro, essa planta começou a ser cultivada na floresta amazônica com fins ilícitos, e a ela se somaram culturas como a papoula, ambas destinadas na atualidade, principalmente, à fabricação de entorpecentes (PNUMA, OTCA e Universidade do Pacífico, 2008).

Amparados na incipiente presença do Estado, nas características geográficas e ambientais dos espaços amazônicos e nas condições de penúria nas quais vivem - em geral- as populações amazônicas, os ilícitos transnacionais se expandiram regionalmente (PROCÓPIO e VAZ, 1997).

Durante as décadas de 1970-1980 houve um paulatino incremento em algumas áreas amazônicas dos cultivos de coca. Isso foi especialmente notório na Bolívia, na Colômbia e no Peru², chegando ao seu auge nas décadas de 1990 e na primeira década

\footnotetext{
${ }^{1}$ Doutoranda em Relações Internacionais e Desenvolvimento Regional. UnB.

2 Jazadji (2012) informou que o Escritório das Nações Unidas Sobre Drogas e Crimes (UNODC) constatou que o Peru expandiu em 6,8\% sua plantação de coca em 2009, em comparação a 2008, com produção da folha estimada em 119 mil toneladas. A Colômbia, no período, produziu 103 mil toneladas. Dessa forma, o Peru ultrapassou a Colômbia, tornando-se o maior produtor mundial da folha de coca.
} 
do ano 2000 (PIZARRO, 2006; PROCÓPIO; 2009). Devido ao aumento constante desses plantios, criaram-se alguns programas como a UNODOC $^{3}$, em 1998, para monitorar o avanço e localização de cultivos ilícitos.

No contexto amazônico, especialmente na Amazônia colombiana ${ }^{4}$ e peruana ${ }^{5}$, existem diversos atores vinculados a esses ilícitos: grupos subversivos, paramilitares e narcoguerrilha, entre outros, que têm sido os responsáveis pelo aumento dos plantios, pelo fortalecimento e expansão do narcotráfico e pelo recrudescimento da violência nos espaços amazônicos. A seguir faz-se uma descrição dos impactos hidrosocioambientais.

\section{CENÁRIO AMAZÔNICO: OS CULTIVOS ILÍCITOS E OS IMPACTOS SOCIETAIS E HIDROAMBIENTAIS}

Em tal âmbito, se produzem profundas mudanças culturais e societais entre as populações locais e indígenas (VIECO, 2001), entretanto, não menos importantes são as nefastas consequências hidroambientais tanto dos plantios de coca como do combate às culturas ilícitas com herbicidas tóxicos, entre eles o glifosato (MONTANA, 2012).

O cultivo da coca e o processamento da planta em cocaína provocam grande número de impactos nos espaços amazônicos de forma local e regional. Isto porque os impactos da plantação da coca estão relacionados com o desmatamento, com a erosão, com a destruição de áreas de preservação ambiental e com a destruição de importantes ecossistemas amazônicos, que integradamente constituem impactos ambientais, hídricos e sociais, muitas vezes não percebidos (MONTANA, 2012).

Sabe-se que o processamento da pasta de cocaína é devastador para a ambiência, sendo que tais atividades afetam as regiões em que são desenvolvidas tanto pela deterioração do solo como pela deterioração dos corpos hídricos e do ar. No processo de

Já na Bolívia, cuja ação antidroga até provocou embate da recente eleição presidencial brasileira, a área dedicada ao cultivo da planta aumentou $1 \%$. Apesar dessas cifras, Colômbia é ainda o país que dedica o maior território ao cultivo da coca - 68 mil hectares -, mas a queda de produtividade das plantações, que diminuíram em escala, projeta a supremacia peruana.

${ }^{3}$ Em 1998 foi criado o Programa de Monitoramento de Cultivos Ilícitos (PMCI) para a coleta e análises de dados sobre os cultivos ilícitos. O PMCI atualmente cobre sete países: Colômbia, Bolívia e Peru para coca, Afeganistão, Laos e Mianmar para papoula e Marrocos para macinha; recentemente UNODC iniciou monitoramento de cultivos de coca no Equador.

${ }^{4}$ Pizarro (2006:146) afirma que "os movimentos guerrilheiros e grupos paramilitares incorporaram-se na década de 1980 ao complexo mundo do narcotráfico, desempenhando papeis diferenciados de acordo com as diversas etapas da cadeia produtiva do narcotráfico".

5 No caso peruano, conforme Jazadji (2012), o recrudescimento da plantação de coca é atribuído a despreparo e corrupção das forças policiais e à transmutação em narcotraficantes de remanescentes da guerrilha Sendero Luminoso. 
conversão da planta em cocaína, é necessária a utilização de muita água e de diversos produtos químicos como querosene, ácido hidroclórico, ácido sulfúrico e cetona, entre outros, os quais acabam vertendo aos rios, igarapés, lagos e águas subterrâneas, destruindo importantes ecossistemas aquáticos e terrestres; dessa forma afetando a biodiversidade, devido à perda inestimável da flora e fauna (Pnuma, OTCA e Universidade do Pacífico, MONTANA, 2012). Paralelamente, essas substâncias afetam drasticamente a qualidade dos solos, provocando inclusive esterilização (ESQUIVEL, 1998; FEARNSIDE, 2003; RÍOS, 2008).

Nesse último aspecto, as pesquisas do PNUMA, OTCA e Universidade do Pacífico (2008) foram enfáticas ao apontar que os cultivos ilícitos repercutem em forte erosão dos solos, tanto pelo manejo inadequado de químicos prejudiciais à ambiência como pelo estabelecimento de culturas em áreas extremamente íngremes, que deveriam funcionar como mata de proteção ao solo. A mesma fonte indicou que a troca da vegetação nativa pela cultura da coca implica no aumento do desmatamento e no incremento de despejo de cargas poluentes nas águas e no aumento da emissão de gases de efeito estufa na região. Em tal sentido, as pesquisas de Ríos (2008) e de Fearnside (2003) também mostraram que, devido à adição de produtos químicos usados na produção dos entorpecentes, existe acúmulo de $\mathrm{CO}^{2}$ na atmosfera, contribuindo para o efeito estufa, responsável pelo aquecimento global.

O desmatamento por causa de plantios de coca foi monitorado pelo SIMCI II (2005) - Sistema Integrado de Monitoramento de Cultivos Ilícitos -, estimando que as áreas desmatadas na Amazônia Boliviana, Colombiana e Peruana, para o plantio de culturas ilícitas, variam entre 200 e 500 quilômetros quadrados em cada país, dependendo do ano avaliado e da fonte consultada.

Se os resultados das pesquisas ora mencionadas são preocupantes, pelos evidentes danos sócio-ambientais, devem ser acrescentados os impactos decorrentes do uso de herbicidas e do glifosato. Tóxicos aplicados massivamente para combater os plantios ilícitos, especialmente na Colômbia, país onde seu uso foi incrementado, ao entrar em vigor o Plano Colômbia, em 2000, programa que conta com o apoio dos Estados 
Unidos ${ }^{6}$ para erradicar as plantações de coca e o combater o narcotráfico na região. Cabe destacar que essa medida foi tomada, de um lado, devido à força do narcotráfico e aos atores da violência no país, sabidamente as narcoguerrilhas. Por outro lado, devido ao aumento dos cultivos (em 22 dos 32 estados na Colômbia há plantações ilícitas), conforme os dados da UNODC (2009).

De acordo com os dados do Pnuma, OTCA e Universidade do Pacífico (2008), na Colômbia houve aumento significativo das plantações dos cultivos ilícitos. Enquanto em 1985 as plantações respondiam por uma área de 15.600 hectares, em 2005 alcançaram 85.750 hectares. Isso significa que a superfície cultivada com coca cresceu 4,5 vezes ao longo de 19 anos. Há que lembrar que nesse período de tempo houve no país a consolidação de grupos guerrilheiros e de paramilitares, grupos que dominaram até tempo recente o espaço amazônico sob um regime de terror e coerção (VIECO, 2001). Lembre-se também de que o narcotráfico é a fonte de ingresso para vários desses grupos, conforme salientado por Pizarro (2006), especialmente das FARC, grupo que dominou boa parte do espaço territorial da Amazônia colombiana. Existem também outros grupos, como o ELN, vinculados a esses ilícitos transnacionais.

Para Vieco (2001), até o final de 1980 os cultivos de coca e a expansão da área sob o domínio das guerrilhas na Amazônia oriental colombiana cresceu e se estendeu até os estados de Guianía e Vaupés, posteriormente atingiu o estado de Amazonas, em menor escala. O aumento significativo dessas culturas na Colômbia levou o governo colombiano a tomar medidas de erradicação dos cultivos ilícitos por meio de aspersões aéreas com glifosato, tal como destacado anteriormente. A Colômbia também tomou medidas militares de combate ao narcotráfico, especialmente na área sul do país, sendo um foco importante de ação, a região de Putumayo, fronteira com Equador.

O governo colombiano, pressionado com o incremento desses índices, viu-se forçado a implementar, no ano 2000, o Plano Colômbia, medida que resultou em vários conflitos políticos com o Equador, e que culminaram numa demanda ante a Corte de Haia, contra o Estado colombiano, em 2008, pelos danos ambientais e humanos, provocados pelas aspersões aéreas com glifosato na área de fronteira.

\footnotetext{
${ }^{6}$ Desde a sua criação, em 2000, os EUA já destinaram cerca de US\$ 5 bilhões ao país andino, para o combate ao cultivo ilegal da coca, e a traficantes, guerrilheiros e paramilitares, que fornecem cerca de 90\% de toda a cocaína consumida pelos estadounidenses, conforme assinalado por Monteiro (2008).
} 


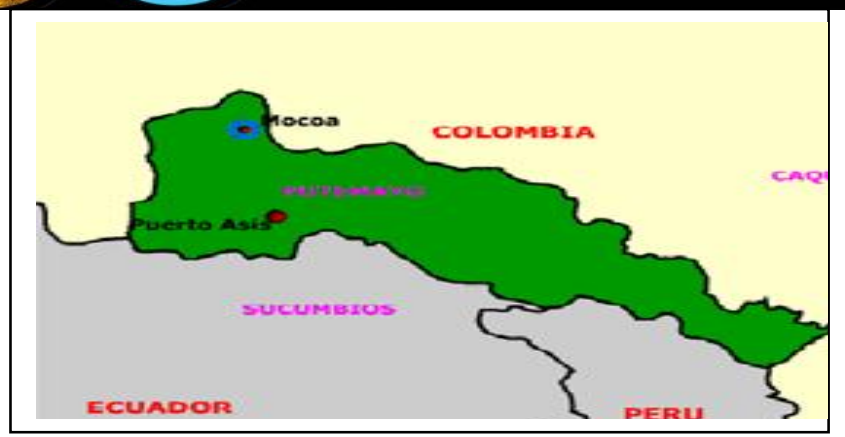

Figura 1. Área de fronteira Colômbia-Equador Fonte: Wykipedia

$\mathrm{O}$ incremento dos graves problemas causados pelo plantio e pelo processamento da coca na Colômbia teve foco no Departamento de Putumayo, estado identificado como produtor de mais de $50 \%$ da coca no país (MONTEIRO, 2008). Esse incremento justificava a focalização das aspersões aéreas com glifosato naquele lugar. Porém, a localização de Putumayo, como mostra a figura 1, é uma área de fronteira internacional da Colômbia com o Equador e o Peru, tornando preocupante para seus vizinhos uma intervenção de tamanha magnitude, pelos então ainda não conhecidos riscos dos efeitos ambientais e hídricos que as aspersões aéreas com esse tóxico traziam para os ecossistemas e para a saúde da população. Mas, sobretudo, temia-se pelas consequências negativas que a militarização das áreas de atuação das narco-guerrilhas na Colômbia poderiam trazer aos países fronteiriços, nas áreas amazônicas.

Um decréscimo dos cultivos ilícitos na Colômbia foi registrado pelo UNODC (2009), no período de 2002 a 2009, tendo um leve incremento nos anos 2005 e 2007. Esse resultado está basicamente associado à erradicação manual da coca e aos processos de aspersão aérea ${ }^{7}$. Já no Peru, tal como apontado por Jazadji (2012), houve incremento dos cultivos e, em países como Equador, algumas áreas apresentavam a presença dos cultivos ilícitos. Entretanto, a decisão de combater os cultivos ilícitos na área de fronteira com Equador por meio do glifosato provocou efeitos colaterais em ambos os países, além de várias tensões políticas na região.

As medidas de repressão, para combater os cultivos ilícitos e o narcotráfico, no âmbito do Plan Colombia, ocasionou tensões diplomáticas entre Equador e Colômbia,

\footnotetext{
${ }^{7}$ De acordo com o informe (2009:10) “En el periodo 2008 - 2009, el área total de cultivos de coca se redujo a 68.000 hectáreas, con lo cual semantiene la tendencia a la reducción iniciada en el periodo 2007 - 2008. Esta disminución representa el 16\% comparado con las 81.000 hectáreas del año anterior y constituye el nivel de cultivos de coca más bajo desde que UNODC mide este fenômeno".
} 
III SEMINÁRII ECDLOGIA

POLÍTICA

tanto pela aplicação das aspersões como pelas intensas ações militares, que, provocavam migração de populações e narco-guerrilheiros para o território equatoriano. Isto porque, na medida em que os plantadores eram pressionados (as narcoguerrilhas), estas passaram a migrar para as áreas de fronteira com o Equador. A presença das FARC no território equatoriano provocou uma série de desavenças, em 2007, entre o Presidente Álvaro Uribe da Colômbia e o Presidente Rafael Correa, do Equador.

Essas tensões se intensificaram em 2008, causando dois sérios conflitos diplomáticos entre as duas nações, consequência dos impactos na população devido às aspersões aéreas e outra da estratégia militar para combater a narcoguerrilha, como será detalhado a seguir, que culminou com a morte do guerrilheiro Raúl Reyes em território equatoriano.

\section{Atuação das Organizações não governamentais}

A utilização do método de aspersões aéreas para erradicar os cultivos ilícitos na Colômbia utilizando glifosato foi amplamente criticada pelos os movimentos sociais e as ONGs no Equador. Esses atores se articularam para exercer pressão ao governo equatoriano em defesa das populações amazônicas afetadas em sua saúde e formas de subsistências por aquele tóxico. As pressões internas no Equador, por causa disso, provocaram vários esforços diplomáticos para que os dois países tentassem um acordo para por fim às aspersões.

Com a implementação do Plano Colômbia diversas pesquisas foram realizadas no Equador para determinar a causa de algumas alterações na saúde da população. Nesse sentido, foram realizados estudos em populações de Sucumbíos, a $5 \mathrm{~km}$ do limite colombiano, uma vez que, entre 2001 e 2003, 16 pessoas faleceram vítimas de intoxicação química (Monteiro, 2005). Foram detectadas também dezenas de casos de intoxicação, não apenas em pessoas cujas análises de sangue demonstraram altas concentrações de glifosato e outros pesticidas, substâncias utilizadas nas aspersões, mas também índices altos de contaminação deste herbicida em cultivos e criações de gado doméstico.

Assim, ao final de 2003, Equador e Colômbia acordaram em estabelecer uma comissão científica e técnica, formada especialmente para investigar os efeitos das aspersões no Equador. As delegações também não conseguiram chegar a um acordo 
quanto aos efeitos desse tipo de aspersões, e o Equador seguiu promovendo denúncias a respeito dos efeitos nocivos das ações colombianas, enquanto Colômbia era obrigada a seguir seu combate ao narcotráfico e os cultivos, por meio das aspersões com glifosato.

Desde 2004, a grave situação de instabilidade interna vivenciada pela Colômbia, na área de fronteira, refletiu-se negativamente no relacionamento com o país vizinho, que, além das reclamações pelos efeitos das aspersões, queixava-se do aumento de migrantes colombianos para o território equatoriano, por causa da violência. Além disso, reclamava das incursões militares realizadas por ordem do governo de Uribe, sem autorização expressa das autoridades equatorianas, para combater a narcoguerilha.

Devido a essas pressões, em dezembro de 2005, a pedido do governo equatoriano, as aspersões com glifosato foram suspensas nas áreas colombianas limítrofes com o Equador, mas de forma temporária, em função das constantes pressoes norteamericanas $^{8}$ pelo combate ao narcotráfico. Assim, em dezembro de 2006 a Colômbia viu-se obrigada a retomar esse procedimento, que continuava a incluir o glifosato, o que acarretou a reação dos vizinhos equatorianos, que já haviam solicitado ao governo colombiano que cessassem as aspersões com esse tóxico de forma definitiva, com base na periculosidade do uso daquele químico. Cabe destacar que, naquele ano, apesar dos esforços colombianos para erradicar manualmente os cultivos da planta (Casa de Nariño, 2008), registrou-se no país um aumento de 26\% desses cultivos. Colômbia, de acordo com MONTEIRO (2008), manteve-se a maior produtora mundial de coca entre 2004 e 2005. Esse fato motivou as pressões estadounidenses para retomar o combate aos cultivos ilícitos.

Em 2007, o presidente equatoriano recém-eleito, Rafael Correa, pressionado pelas ONGs ambientalistas atuantes no Equador e por reconhecidas denúncias sociais, deu início a um processo de reclamações ante a Colômbia, que pode ser interpretado em dois sentidos: a) pelo uso desse herbicida; b) pela adoção do Plano Colômbia - baseado em operações militares, com o apoio dos Estados Unidos, de combate ao narcotráfico e aos cultivos ilícitos. Assim, Rafael Correa levou a Colômbia à Corte Interamericana de Direitos Humanos, face aos malefícios causados pelos herbicidas à população, e à

\footnotetext{
${ }^{8}$ Desde a criação do Plano Colômbia, os EUA já destinaram cerca de US 5 bilhões ao país andino para o combate ao cultivo ilegal da coca, e a traficantes, guerrilheiros e paramilitares, que fornecem cerca de 90\% de toda a cocaína consumida aos estadunidenses (MONTEIRO, 2008).
} 
produção agrícola da fronteira equatoriana, com base num relatório emitido pela Comisión Científica Ecuatoriana intitulado El Sistema de Aspersiones Aéreas del Plan Colombia y sus Impactos sobre el Ecosistema y la Salud en la Frontera Ecuatoriana.

Esse documento visava a contrapor-se à argumentação do governo colombiano que subestimava a periculosidade dos herbicidas e do glifosato. Recomendava-se ao governo colombiano que as aspersões aéreas preservassem uma faixa de $10 \mathrm{~km}$ a partir do limite internacional entre Equador e Colômbia, de modo a não afetar a população equatoriana nas fronteiras, o que não foi atendido pela Colômbia, tal como argumenta o governo equatoriano.

Naquele processo, a articulação de movimentos sociais e ambientalistas, bem como dos meios acadêmicos e de ONGs equatorianas comprometidas com os direitos humanos e, particularmente, com direitos indigenistas, foi fundamental para que esses fatos chegassem ao nível de discussão política interestatal. Ora pelas consequências sobre a saúde humana, animal e da ambiência, ora pelos efeitos colaterais dos mecanismos de combate aos cultivos ilícitos, ao narcotráfico e à narcoguerrilha.

O Programa Andino para la Democracia y los Derechos Humanos de la Unión Europea en Colombia, teve papel importante na apresentação de diversas bases científicas contra o uso do glifosato, bem como vários grupos epistêmicos de reconhecidos centros acadêmicos colombianos.

A Defensoría del Pueblo del Ecuador, alicerçada em um estudo científico realizado em 10 mulheres equatorianas e 12 colombianas, entregue ao governo do Equador, apresentou provas de que o uso de glifosato tem sérias consequências sobre a saúde, relacionadas com o câncer e a malformação de crianças indígenas ${ }^{9}$. A área de estudo foi em localidades próximas ao rio San Miguel. No estudo foi mostrado que a incidência desses fenômenos emerge com o inicio das aspersões com glifosato (Montana, 2012).

Outros estudos realizados no rio Putumayo também revelaram alterações no ecossistema aquático e terrestre. Além das plantações queimadas, pelo efeito do

\footnotetext{
${ }^{9}$ Ver relatório Daños genéticos en la frontera con Ecuador por fumigaciones del Plan Colombia (http://www.accionecologica.org/descargas/areas/fumigaciones_plancolombia/documentos/docu/02-

Danio\%20genetico\%20en\%201a\%20frontera-definitivo.doc). No informe consta: Hay eminente factor de riesgo de cáncer y de malformaciones fetales. El daño genético en estas mujeres es 800 por ciento superior al de mujeres analizadas por el laboratorio de Quito y 500 por ciento superior al hallado en poblaciones de similares características en la región amazónica, a 80 kilómetros de la zona de estudio.
} 
glifosato, o veneno se mostra altamente lesivo no meio aquático, destruindo as espécies mais sensíveis a seu efeito, provocando desequilíbrio nos ecossistemas, tal como afirma a Defensoría del Pueblo del Ecuador. Com base nesses estudos preliminares, iniciaramse as controvérsias sobre os efeitos desse herbicida, que, posteriormente, vieram a ser ratificados por estudos mais sofisticados, solicitados pela Defensoría del Pueblo del Ecuador, numa amostra maior de mulheres e crianças, realizadas em estudos sanguíneos. Apesar desses estudos, Colômbia e os Estados Unidos apresentaram argumentações de que o uso de herbicidas ligados com glifosato não têm impactos severos e nem permanentes, defendendo seu uso por ser inofensivo à saúde humana.

Com as duas nações embuídas de perspectivas opostas, a iniciativa de tentar resolver essa questão por via diplomática também não rendeu uma solução para o problema, ou sequer a produção de um texto para uma ata conjunta de compromissos.

Em 28 de maio de 2007, o ministro das relações exteriores da Colômbia, Fernando Araújo Perdomo, afirmou em uma reunião entre os países que a Colômbia não estava em uma posição de fazer compromissos com relação ao tema das aspersões, tampouco de predizer o que deveria ser decidido no futuro em relação ao tema. Diante disso, o Equador informou à Colômbia, em nota diplomática expedida em 27 de julho de 2007, que considerava esgotado o processo de diálogo, já que não havia perspectivas de êxito (Montana, 2012).

Conforme o pronunciamento da Casa de Nariño, em Bogotá, em 31 de março de 2008, essa atitude tomada pelo governo colombiano teria uma explicação: o presidente Correa exigia um compromisso, por escrito, de que cessariam as aspersões numa faixa não inferior de $10 \mathrm{~km}$ de sua fronteira, para desistir de sua demanda contra a Colômbia. A resposta colombiana foi a de incrementar programas de erradicação manual, mas considerou inadequado adquirir um compromisso sem limite de tempo, principalmente argumentando os riscos, os custos em matéria de segurança e de vidas humanas que tem significado os programas de erradicação manual, já postos em prática na área de conflito ${ }^{10}$.

\footnotetext{
10 Além dos 40 casos registrados pelo governo colombiano de ataques das FARC desde território equatoriano, foi lembrado que os atos terroristas se incrementaram em finais de 2007 e começos de 2008 porque as FARC ativavam minas anti-pessoais contra os militares que protegiam os erradicadores manuais de coca em território colombiano, elevando as cifras de mortes na área. Pronunciamento oficial da Casa de Nariño, em Bogotá, em 31 de março de 2008.
} 
Apesar disso, houve um reconhecimento por parte da Colômbia de estar afetando a saúde da população equatoriana, confirmando ao Equador o pagamento de indenizações. Entretanto, justificou a impossibilidade de intensificar programas de erradicação manual da coca, uma vez que as áreas com cultivos ilícitos são extensas e a erradicação manual não apresentaria os resultados esperados.

Adicionalmente, foi argumentado que os programas desse tipo somente incrementaram a violência na região, aludindo-se à periculosidade dessa medida para as forças militares, policiais e para a população civil, uma vez que, em diversas ocasiões, as FARC atacaram tanto militares como civis, tendo sido contabilizados pelo governo colombiano vários ataques da guerrilha, que foram incrementados desde o ano 2004 quando as aspersões foram menos constantes.

O ano de 2007 terminou com evidentes tensões entre os dois países. De uma parte estava o assunto delicado das aspersões com glifosato, implicando a demanda; da outra, a incursão guerrilheira no território equatoriano. Além disso, começaram naquele período mútuas e agressivas acusações entre os dois representantes do governo devido a suas posições políticas divergentes, as quais eram atiçadas pelo apoio que o presidente Hugo Chávez manifestava às FARC, criticando abertamente os métodos do Plano Colômbia.

As estratégias adotadas por Álvaro Uribe, com o apoio dos Estados Unidos, de combater militarmente tanto a insurgência instalada há décadas no país, quanto ao narcotráfico, através do método das aspersões aéreas, eram amplamente criticadas por parte dos presidentes de Equador e Venezuela. A isso somavam-se as acusações do suposto vínculo de Uribe com as autodefesas. O que mais era debatido era o fato de se implantarem métodos para combater ilícitos, permitindo o ingresso dos americanos na Amazônia colombiana.

Por sua vez, Uribe respondia que o governo do Equador (por convicção ou omissão) dava cobertura aos narcoguerrilheiros colombianos, permitindo que um mal que carcomia o povo colombiano se alastrasse regionalmente a outros territórios. Assim, em vários discursos públicos Uribe deixava em entrelinhas que sabia que insurgentes das FARC estavam instalados no território vizinho. As relações entre Equador, Colômbia e Venezuela passaram a ser delicadas pelas manifestações de apoio, também 

A decisão do Estado equatoriano não foi um ato aleatório, já que foram várias as tentativas de negociar com a Colômbia o fim das aspersões. O processo instaurado pelo Equador, argumentando dano transfronteiriço, ocasionado pelas aspersões aéreas, é uma mostra da evolução da preocupação com esses tipos de conflitos. Seu ineditismo poderá converter-se num ícone em matéria jurídica ambiental e de direitos humanos na América do Sul.

Apesar de não ter sido julgado, em 2009, no mês de maio, os países envolvidos apresentaram o memorial. Trata-se de um documento no qual são apresentadas todas as provas para o caso a ser julgado. Conforme o embaixador Cordovez, existem provas técnicas que demonstram que o espaço aéreo do Equador foi violado repetidas vezes pelas naves que aplicavam o glifosato. Além disso, os relatórios científicos apresentam suficientes provas da periculosidade do glifosato para a ambiência, os ecossistemas aquáticos, terrestres e para a população.

Apesar de que as petições realizadas pelo Equador se distanciam do tema que originou a crise, parece claro, não obstante, que a demanda é uma resposta às operações que produziram a morte de 'Raúl Reyes' em território equatoriano. Isso pode se deduzir porque nas duas últimas reuniões da Comisión Asesora de Relaciones Exteriores (dezembro de 2007 e março de 2008) o tema foi mencionado, ao menos de maneira tangencial. Mas, como adverte González (2009), citado por Montana (2012) "para estas dos fechas, Ecuador no tenía herramientas para proceder contra Colombia". Esse autor explica que:

La Corte Internacional de Justicia sólo asume la competencia para conocer los casos cuando existen tres circunstancias: cuando las partes llegan de común acuerdo y solicitan su intervención, que no es el caso; cuando los dos países han aceptado la competencia previamente por declaraciones unilaterales, que tampoco es aplicable pues ninguna de los dos -ni Colombia ni Ecuador-tiene vigente tal instrumento. $Y$, finalmente, por aplicación de un Tratado que, como el Pacto de Bogotá, así lo disponga. Pero mientras Colombia era parte formal del Tratado, Ecuador, hasta el 1 de marzo pasado, no era parte.

Para Montana (2012), existe um vínculo muito estreito entre os dois processos, já que Equador vinha estudando por meios jurídicos a forma de estabelecer a demanda.

Cabe lembrar que, em 14 de janeiro de 2008, os presidentes Uribe e Correa tinham se reunido durante a posse do novo presidente da Guatemala, Álvaro Colón, e que naquela ocasião o presidente Uribe ratificou o oferecimento de indenizar, de acordo 
III SEMINÁRII ECDLOGIA

POLÍTICA

com a lei colombiana, aos cidadãos equatorianos que houvessem sofrido algum prejuízo por causa das aspersões aéreas. Conforme a Casa de Nariño, apesar dessa atitude do governo colombiano, nenhuma solicitação formal foi apresentada pelo presidente Correa, com respeito aos danos causados à população.

Foi proposto que se implementasse um acordo entre os governos através das chancelarias, sem qualquer avanço. Com respeito ao caso do ataque em Sucumbios, o presidente equatoriano solicitou uma reunião urgente da OEA e da Comunidade Andina de Nações CAN para tratar do ataque colombiano. Em sua defesa, Álvaro Uribe alegou ter provas contundentes que ligavam os dois países Venezuela e Equador às FARC. Dessa forma, Uribe argumentou que a ação colombiana foi um ato de legítima defesa do país. Como era de se esperar, as acusações de Uribe foram mal recebidas em Quito, que considerou as argumentações do governo uma artimanha para esconder a flagrante violação da soberania equatoriana.

Apesar do governo equatoriano negar a associação de ser a denuncia em Haia uma retaliação pela violação do espaço aéreo e territorial, no caso de Sucumbios, resulta difícil não estabelecer uma correlação.

Os problemas locais, como se ressalta nesta oportunidade, desencadearam tensões diplomáticas fortes entre Colômbia, Equador e Venezuela, colocando em perigo a segurança regional e os empreendimentos políticos de integração almejados na União de Nações Sul-Americanas (UNASUL). Mas, por outro lado, chamou a atenção para um problema que raramente cobra a atenção merecida da Comunidade Internacional, especialmente se tratando de impactos hidroambientais ou hidrosocioambientais, como no caso aqui tratado.

\section{REFERÊNCIAS BIBLIOGRÁFICAS}

CASA DE NARIÑO - REPÚBliCA DE COLÔMBIA. Porta Voz de Prensa. Www.presidencia.gov.co

COMISIÓN CIENTÍFICA ECUATORIANA. EI Sistema de Aspersiónes Aéreas del Plan Colombia y Sus Impactos sobre el Ecosistema y la Salud en la Frontera Ecuatoriana. Quito: 2007. Disponível em www.mamacoca.org. Acesso em março de 2011. 


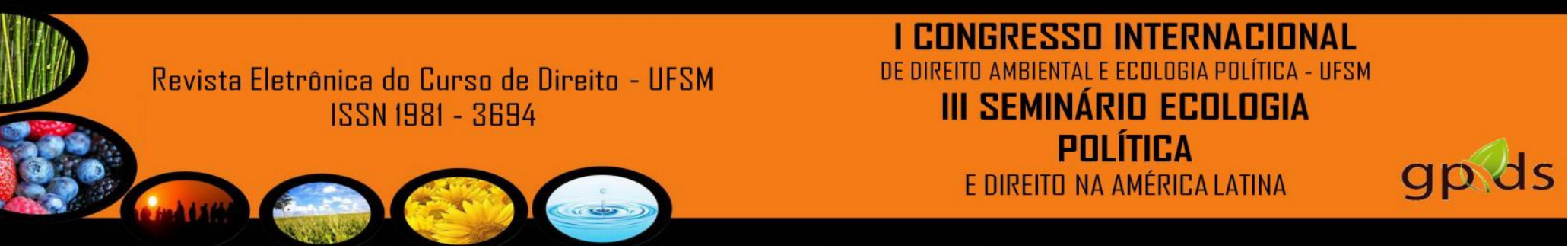

Defensoría del Pueblo Ecuador. Relatorio Daños genéticos en la frontera con Ecuador por fumigaciones del Plan Colombia. Disponível em: http://www.accionecologica.org/descargas/areas/fumigaciones_plancolombia/document os/docu/02-Danio\%20genetico\%20en\%20la\%20frontera-definitivo.doc).

FEARNSIDE, P. M. A Floresta Amazônica nas Mudanças Globais. Manaus: INPA, 2003.

JAZADJI, A. Coca: Peru passa Colômbia. São Paulo. 2012. Disponível em: http://www.afanasio.com.br/Artigos/Artigo211.htm. Acessado em setembro 2012.

MONTANA, M. Bacia Amazônica e Hidropolítica: Interdependência Hidrológica, Incipiente Regime Regional e Baixo Conflito. Tese. Universidade de Brasília. Brasília. 2012.

MONTEIRO, L. C. Equador e Colômbia: antecedentes de um conflito anunciado. Revista Eletrônica Boletim do Tempo Presente, n.5.2008. <http://igeoserver.igeo.ufrj.br/retis/wp-content/uploads/2008-Equador-e-Colo\%CC\%82mbia-

LCRM.pdf>. Acesso em fevereiro de 2011.

PIZARRO, E. Uma Democracia Sitiada. Biblioteca do exército Editora. Rio de Janeiro. 2006.

PROCÓPIO, A. Subdesenvolvimento Sustentável. Juruá Editora. 2007.

2009.

Quo Vadis, Amazonia? Grupo Editor Latinoamericano. Buenos Aires.

PROCÓPIO, A. VAZ, A. Brasil e o narcotráfico internacional. Revista Brasileira de Política Internacional, n. 40, vol 1, pp. 75-122. 1997.

Programa das Nações Unidas para o Meio Ambiente - PNUMA, Organização do Tratado de Cooperação Amazônica - OTCA e Universidade do Pacífico. Perspectivas do Meio Ambiente na Amazônia. GEOAMAZONIA. Brasília. 2008.

RÍOS, J. Armazenamento de Carbono e Valoração Econômica em Sistemas de Usoda-Terra com o Cultivo da Coca (Erythroxylon coca Lam.) no Distrito de José Crespo e Castillo, Peru. Ministério de Educação Universidade Federal Rural da Amazônia EMBRAPA - Amazônia Oriental. Belém. 2008.

RIPPEL, M. O Plano Colômbia como instrumento da política norte-americana para a América Latina e suas consequências. Escola de Guerra Naval, 2004. Disponível em: <http://www.egn.mar.mil.br/arquivos/cepe/ensaioCcRippel.pdf>. Acessoem março de 2012.

VIECO, J.J. Desarrollo, Medio Ambiente y Cultura en la Amazonía Colombiana.

Rev. Salud Pública; 3(supl.1): 2-23, jan. 2001. Disponível em

http://www.revmed.unal.edu.co/revistasp/v3n1s/v3ss1.htm. Acesso em maio de 2011. 